\title{
Predictive value and limitations of the ST/HR slope
}

\author{
OLIVIER AMEISEN, PETER M OKIN, RICHARD B DEVEREUX, CLARE HOCHREITER, \\ DAVID H MILLER, MICHAEL A ZULLO, JEFFREY S BORER, PAUL KLIGFIELD \\ From the Division of Cardiology, Department of Medicine, New York Hospital-Cornell Medical Center, New York, \\ USA
}

SUMmaRY To assess the value and predictive limitations of the exercise ST/HR slope, exercise test results were compared in 50 patients with stable angina and in 17 normal subjects with those in two groups known to have a high prevalence of inaccurate electrocardiographic responses to exercise. The last two groups included 51 patients tested within three weeks of acute myocardial infarction and 17 with important aortic regurgitation but no coronary disease. Of the normal subjects, 16 (94\%) had ST/HR values $\leqslant 1 \cdot 1 \mu \mathrm{V} /$ beat/min. Of those with stable angina pectoris, 42 of $46(91 \%)$ patients with coronary artery disease had ST/HR slopes ranging from 1.2 to $20.0 \mu \mathrm{V} / \mathrm{beat} / \mathrm{min}$, with false negative findings (slopes $\leqslant 1 \cdot 1 \mu \mathrm{V} / \mathrm{beat} / \mathrm{min}$ ) in only four $(9 \%)$. In contrast, of those with recent myocardial infarction, 15 of $42(36 \%)$ with coronary disease had false negative slopes, including 12 of $20(60 \%)$ with anterior wall injury. Of those with aortic regurgitation, conversely, 14 of $16(88 \%)$ patients with calculable ST/HR slopes had values $>1 \cdot 1 \mu \mathrm{V} /$ beat/min despite the absence of coronary disease.

Despite the accuracy of the test in patients with stable angina, false negative results are common in those after recent myocardial infarction, and false positive results occur often in those with abnormal volume loading due to aortic regurgitation.

The rate related change in ST segment depression during exercise (the ST/HR slope) has been shown by Elamin et al and Kardash et al to identify accurately patients with coronary artery disease and to categorise patients with stable angina according to the extent of coronary disease. ${ }^{1-3}$ In patients evaluated by treadmill exercise electrocardiography using a modified ST/HR slope analysis based on three electrocardiographic leads, we have found that this new method can improve the sensitivity, specificity, and predictive value of the exercise electrocardiogram for identifying three vessel coronary artery disease in patients with stable angina. ${ }^{4}$

Nevertheless, both the theoretical basis ${ }^{5}$ and clinical applicability ${ }^{7}$ of this technique have been challenged. Attempts by others to reproduce the perfect test accuracy of the ST/HR slope, using original bicycle exercise methodology, have been less successful, 67 and we have also found false positive and false nega-

Requests for reprints to Dr Paul Kligfield, Division of Cardiology, Department of Medicine, The New York Hospital-Cornell Medical Center, 525 East 68 Street, New York, New York 10021, USA.

Accepted for publication 7 December 1984 tive test responses in relation to the extent of coronary disease that require further evaluation. To assess possible sources of error that might affect the applicability of the ST/HR slope as a test we compared the results in normal subjects (group 1) and patients with stable angina (group 2) with those in two groups of patients known to have a high prevalence of inaccurate electrocardiographic responses to exercise, those examined before hospital discharge after acute myocardial infarction (group 3) and those with important aortic regurgitation who had no coronary disease (group 4).

\section{Patients and methods}

\section{GROUP 1}

Seventeen normal subjects (including $16 \mathrm{men}$ ), whose mean (SD) age was 33 (12) (range 23-57) years, were selected from a clinically normal population with no history, symptoms, or signs of cardiac disease. None underwent coronary angiography. Nevertheless, each subject had a normal resting electrocardiogram and normal $M$ mode echocardiogram. ${ }^{8}$ In addition, each subject had a normal resting and exercise radionuclide cineangiogram, ${ }^{9}$ with a $>5 \%$ increase in left ventricu- 
lar ejection fraction during exercise and no evidence of localised wall motion abnormality. During standard exercise electrocardiography upsloping ST segment depression approaching $0.1 \mathrm{mV}$ was present in two (12\%) but none had horizontal or downsloping ST depression that reached $0 \cdot 1 \mathrm{mV} \cdot{ }^{10}$

\section{GROUP 2}

Fifty patients had stable angina pectoris (including 42 men and eight women) whose mean age was 53 (11) (range 31-74) years. Although $22(44 \%)$ had had a previous myocardial infarction, in none had infarction occurred within two months of exercise testing. All patients underwent coronary angiography, and the extent of disease was graded according to the criteria used by Elamin et al. ${ }^{2}$ Eighteen patients had three vessel coronary artery disease, including five with additional left main stem disease, 22 two vessel disease, six one vessel disease, and four no significant coronary disease. At the time of testing 28 (56\%) patients were taking beta blocking drugs and two (4\%) digitalis.

\section{GROUP 3}

Fifty-one patients had recent myocardial infarction (including 48 men and three women), whose mean age was 51 (10) (range 26-29) years. Each was examined as part of a routine predischarge assessment between 10 and 21 days after admission to hospital for acute myocardial infarction. Twenty-four patients had a recent transmural anterior wall myocardial infarction and 27 other types of infarction including 17 with a recent transmural inferior or true posterior wall infarction and 10 with a recent subendocardial infarction. All patients underwent coronary angiography: nine had three vessel coronary disease, 22 two vessel disease, 17 one vessel disease, and three no significant coronary disease. At the time of testing $11(22 \%)$ were taking beta blocking drugs and five (10\%) digitalis.

\section{GROUP 4}

Seventeen patients had aortic regurgitation (including 13 men and four women), whose mean age was 53 (14) (range 28-71) years. Each was studied as part of a longitudinal study of the natural history of valvar regurgitation. All these patients had haemodynamically important aortic regurgitation without additional valve lesions and were included because of the absence of coronary artery disease when examined at cardiac catheterisation because of symptoms or signs indicating a possible need for aortic valve replacement. At the time of testing one (6\%) patient was taking beta blocking drugs and nine (59\%) digitalis until three days before the test. Data were stratified for possible drug effects on the electrocardiogram.

\section{EXERCISE ELECTROCARDIOGRAPHY}

All exercise electrocardiograms were performed on a treadmill using standard or modified Bruce protocols. ${ }^{11}$ Except in patients with recent myocardial infarction, in whom exercise was limited to $65-75 \%$ of maximum predicted heart rate, maximum heart rates were sought as the exercise endpoint. Tests were stopped if limiting chest pain, a fall in systolic blood pressure, three or more sequential ventricular extrasystoles, or limiting fatigue, dyspnoea, or dizziness occurred. Mean peak heart rates achieved were 177 beats/min in the normal subjects, 125 beats $/ \mathrm{min}$ in patients with stable angina, 122 beats/min in those with recent myocardial infarction, and 153 beats/min in those with aortic regurgitation.

\section{ST/HR SLOPE CALCULATION}

The rate related change in ST segment depression (ST/HR slope) was calculated according to our previously reported modification ${ }^{4}$ of the method developed by Elamin et al and Kardash et al.$^{1-3}$ The magnitude of ST segment depression, to the nearest $25 \mu \mathrm{V}$ $(1 \mathrm{~mm}=100 \mu \mathrm{V})$, was averaged in 3-4 complexes from a point $70 \mathrm{~ms}$ after the J point. ST segment measurements in leads aVF, V5, and V6 were related to heart rate, and the ST/HR slope was calculated from the linear regression data relating these variables. For each lead, the slope derived from linear regression analysis of the final three data points at peak exercise was compared with those obtained by including progressively earlier data. The highest slope with a statistically significant coefficient of linear correlation from among the three leads was selected as the test result. An upper limit of normal $1 \cdot 1 \mu \mathrm{V} /$ beat/min, as previously reported by Elamin et al,,$^{2}$ was taken as accurately identifying normal subjects and those with stable angina pectoris. An ST/HR slope value of $6.0 \mu \mathrm{V} /$ beat/min has previously been found to identify accurately patients with and without three vessel coronary disease among those with stable angina, ${ }^{4}$ and agrees closely with the findings of Elamin et al. 12

\section{DATA ANALYSIS}

Definitions of test sensitivity, specificity, positive predictive value, and overall accuracy conform to standard usage as previously reported. ${ }^{4}$ Mean values are given with the standard deviation (SD) as the index of dispersion, and means were compared using Student's $t$ test for unpaired samples. Proportions were compared using the $\chi^{2}$ test with Yates's correction for continuity.

\section{Results}

The Figure shows the calculated exercise ST/HR 


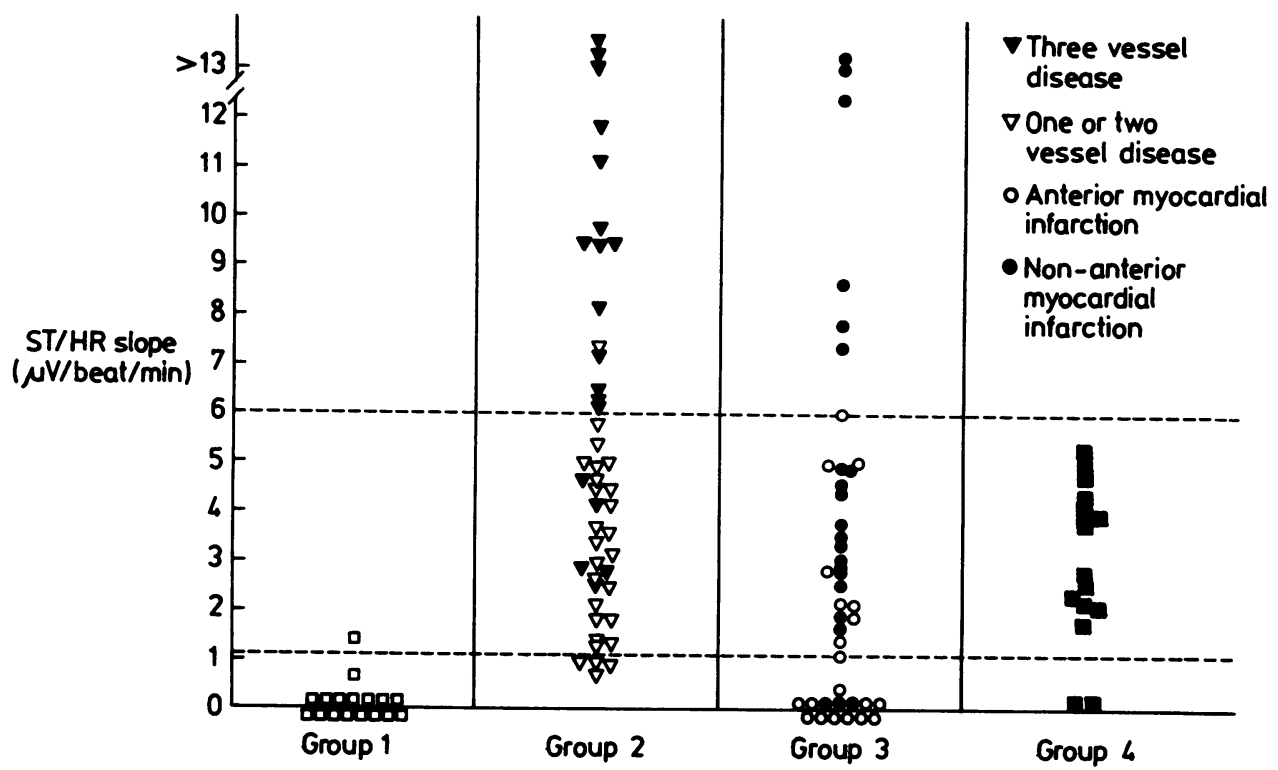

Figure ST/HR slope in 17 normal subjects (group 1), 46 patients with stable angina pectoris (group 2), 42 patients with recent myocardial infarction (group 3), and 16 patients with aortic regurgitation (group 4). A slope of $1 \cdot 1 \mu \mathrm{V} / \mathrm{beat} / \mathrm{min}$ represents the upper limit of normal 12 and a slope of $6.0 \mu \mathrm{V} / \mathrm{beat} / \mathrm{min}$ was used to identify three vessel disease. ${ }^{24}(100 \mu V=1 \mathrm{~mm}$.)

slopes for all four groups of subjects. Using a value of $1.1 \mu \mathrm{V} / \mathrm{beat} / \mathrm{min}$ as distinguishing between normal and abnormal ST/HR slopes in the normal subjects and in the patients with stable angina pectoris due to coronary disease resulted in a test sensitivity of $91 \%$ $(42 / 46)$, a specificity of $94 \%$ (16/17), a positive predictive value of $98 \%$ (42/43), and an overall accuracy of $92 \%(58 / 63)$ in identifying coronary artery disease.

\section{NORMAL SUBJECTS (GROUP 1)}

A statistically valid ST/HR slope could be calculated for all the normal subjects. The mean ST/HR slope in this population was $0.12(0.4)$ (range $0.0-1.4) \mu \mathrm{V} /$ beat $/ \mathrm{min}$. The ST/HR slope was $\leqslant 1 \cdot 1$ in $94 \%(16 / 17)$ of these subjects.

\section{PATIENTS WITH STABLE ANGINA (GROUP 2)}

A statistically valid ST/HR slope could be calculated in all the patients with stable angina pectoris. In this group, 46 (92\%) patients had significant coronary artery disease found at coronary angiography. The mean ST/HR slope in these 46 patients was $5.5(4.4)$ (range 0.7-20.0) $\mu \mathrm{V} /$ beat $/ \mathrm{min}$. Of these, 42 (91\%) had ST/HR slopes $>1.1 \mu \mathrm{V} /$ beat $/ \mathrm{min}$, while only four (9\%) had ST/HR slopes $\leqslant 1 \cdot 1 \mu \mathrm{V} /$ beat $/ \mathrm{min}$.

\section{PATIENTS WITH MYOCARDIAL INFARCTION (GROUP 3)}

Of the 51 patients with recent myocardial infarction, 48 (94\%) had coronary artery disease at angiography after exercise testing. In six (12\%) patients no statistically valid $S T / H R$ slope could be calculated owing to insufficient data points or to non-linear test responses, despite underlying coronary disease in each of these patients. Of the 45 patients with a calculable slope, 42 (93\%) had coronary disease.

The mean ST/HR slope in myocardial infarction patients with coronary disease was 3.8 (5.6) (range $0.0-30.4) \mu \mathrm{V} /$ beat $/ \mathrm{min}$. In contrast to patients with stable angina, $\mathrm{ST} / \mathrm{HR}$ slopes $\leqslant 1 \cdot 1 \mu \mathrm{V} /$ beat $/ \mathrm{min}$ were found in 15 (36\%) of the 42 myocardial infarction patients with coronary artery disease during predischarge exercise testing $(p<0.005)$. False negative values were particularly common among patients after acute transmural anterior wall myocardial infarction, of whom $12(60 \%)$ had ST/HR slopes $\leqslant 1 \cdot 1$ and 10 (50\%) slopes of $0.0 \mu \mathrm{V} /$ beat $/ \mathrm{min}$. In contrast, ST/HR slopes $\leqslant 1 \cdot 1 \mu \mathrm{V} /$ beat $/ \mathrm{min}$ occurred in only three (14\%) of 22 patients with recent inferior or subendocardial myocardial infarction $(p<0.01)$.

\section{PATIENTS WITH AORTIC REGURGITATION (GROUP 4)}

None of the 17 patients with aortic regurgitation had coronary artery disease at angiography. In one patient no statistically valid ST/HR slope could be calculated. Each of the remaining 16 patients had a calculable ST/HR slope (mean 3.i (1.6) (range 0.0-5.3) $\mu \mathrm{V} /$ beat $/ \mathrm{min}$ ). False positive values were common in this group. Despite the absence of coronary disease, 14 
(88\%) patients with haemodynamically important aortic regurgitation had ST/HR slopes $>1 \cdot 1 \mu \mathrm{V} /$ beat/ min compared with only one $(6 \%)$ of the normal subjects $(p<0.001)$. Although over half the patients in this group had been taking digitalis until several days before testing, this could not be implicated as the cause of the false positive ST/HR responses. Mean ST/HR slope in the nine patients recently taking digitalis $(2.9(1.9) \mu \mathrm{V} /$ beat $/ \mathrm{min})$ was no different from that in the seven patients not taking digitalis (3.3 (1.2) $\mu \mathrm{V} /$ beat/min, NS).

\section{Discussion}

Previous studies in Leeds ${ }^{1-3}$ and in our laboratory ${ }^{4}$ have shown that the ST/HR slope can significantly improve the accuracy of exercise electrocardiography in identifying and quantifying coronary disease in patients with stable angina pectoris. As predicted by Fox ${ }^{5}$ and shown by Quyyumi et $a l^{6}$ and by Balcon et al, ${ }^{7}$ however, false positive and false negative test responses for the presence and anatomical extent of coronary disease can occur. This is in striking contrast to the perfect accuracy of the ST/HR slope reported by Elamin et al and Kardash et al . 1-3

Our data suggest that conflicting reports of the applicability of this method might be partly explained by the relation of the ST/HR slope to factors other than the number of obstructed coronary arteries. Although our present findings confirm the ability of the ST/HR slope to distinguish patients with coronary disease and stable angina from normal subjects, it is also apparent that the ST/HR slope is often in the normal range in patients with recent myocardial infarction despite extensive coronary obstruction. Furthermore, we have found that the ST/HR slope is often significantly increased in patients with aortic regurgitation despite the absence of coronary disease.

It is well recognised that exercise electrocardiograms are commonly negative by standard test criteria after myocardial infarction, ${ }^{12-14}$ and the ST/HR slope appears to be similarly limited in accuracy after infarction. False negative responses occurred most often after recent anterior wall injury partly owing to persistent ST segment elevation affecting the anterolateral leads. The applicability of the ST/HR slope after myocardial infarction was further reduced by the high prevalence of incalculable slope values. In contrast, statistically valid ST/HR slopes could be calculated in all patients with stable angina.

Conversely, false positive ST/HR slope responses might be predicted among patients with aortic regurgitation since standard exercise test criteria are often positive in patients with valvar heart disease who do not have coronary disease. ${ }^{15} 16$ Indeed, most patients with aortic regurgitation had ST/HR slope values that were similar to the calculated slopes in our patients with coronary disease. Although some of our patients with aortic regurgitation had recently been taking digitalis, a drug effect cannot explain the electrocardiographic findings since identical changes occurred in the absence of digitalis.

Associated myocardial infarction, additional valvar disease, and a variable prevalence of three vessel disease must therefore be considered in the interpretation of apparently conflicting reports of the accuracy of the ST/HR slope. ${ }^{1-467}$ We agree that perfect results $^{1-3}$ are unlikely with any test, but this issue should not obscure major improvements in overall test accuracy. ${ }^{4}$ The patients studied by Quyyumi et $a l^{6}$ were not characterised with regard to recent myocardial infarction or additional cardiac disease. Although Balcon et $\mathrm{al}^{7}$ excluded patients with valvar disease from their study, ${ }^{7}$ a substantial proportion of their population was reported to have previous myocardial infarction, including their only two patients who had three vessel coronary disease. We have also found an important overlap in ST/HR slope values in patients with one and two vessel disease. ${ }^{4}$ Nevertheless, the unusually low prevalence of advanced coronary disease in patients reported by Balcon et al makes their findings potentially compatible with our finding that the ST/HR slope can improve recognition of three vessel disease in patients with stable angina pectoris.

Our findings therefore show that variability in the extent of the disease can appreciably affect the accuracy and applicability of the ST/HR slope. In ischaemic heart disease, the method appears to be most predictive in patients with stable angina pectoris. In the immediate postinfarction period the accuracy of the test is limited, perhaps because of discordant ST segment responses associated with recent injury and wall motion abnormalities in these patients. Among patients with non-ischaemic heart disease, it is reasonable to predict that further false positive ST/HR slope responses will be found with abnormal loading conditions in addition to aortic regurgitation. The predictive value of the ST/HR slope in hypertension and in the cardiomyopathies remains to be evaluated. We conclude that the patient population must be carefully selected in further evaluations of the ST/HR slope. In addition, the correlation of the ST/HR slope with geometric and functional variables may provide further insight into the mechanism of repolarisation changes in ischaemic and nonischaemic heart disease.

JSB was supported in part by a grant from the National Heart, Lung and Blood Institute, National Institute of Health, Maryland, Bethesda, USA. 


\section{References}

1 Elamin MS, Mary DASG, Smith DR, Linden RJ. Prediction of severity of coronary artery disease using slope of submaximal ST segment/heart rate relationship. Cardiovasc $R$ es 1980; 14: 681-91.

2 Elamin MS, Boyle R, Kardash MM, et al. Accurate detection of coronary artery disease by new exercise test. Br Heart F 1982; 48: 311-20.

3 Kardash M, Boyle R, Elamin MS, Stoker JB, Mary DASG, Linden RJ. Detection of severity of coronary artery disease by the ST segment/heart rate relationship in patients on beta blocker therapy. Cardiovasc Res 1982; 16: 508-15.

4 Okin PM, Kligfield P, Ameisen O, Goldberg HL, Borer JS. Improved accuracy of the exercise electrocardiogram: identification of three vessel coronary disease in stable angina pectoris by analysis of peak rate related changes in ST segments. Am $\mathcal{F}$ Cardiol 1985; 55: 271-6.

5 Fox KM. Exercise heart rate/ST segment relation: perfect predictor of coronary disease? $\mathrm{Br}$ Heart $\mathcal{J}$ 1982; 48: 309-10.

6 Quyyumi AA, Raphael MJ, Wright C, Bealing L, Fox KM. Inability of the ST segment/heart rate slope to predict accurately the severity of coronary artery disease. $\mathrm{Br}$ Heart f 1984; 51: 395-8.

7 Balcon R, Brooks N, Layton C. Correlation of heart rate/ST slope and coronary angiographic findings. $\mathrm{Br}$ Heart f 1984; 52: 304-7.

8 Devereux RB. Echocardiography: state of the art1984. Cardiology 1984; 71: 118-35.
9 Borer JS, Bacharach SL, Green MV, Kent KM, Epstein SE, Johnston GS. Real-time radionuclide cineangiography in the noninvasive evaluation of global and regional left ventricular function at rest and during exercise in patients with coronary-artery disease. $N$ Engl $\mathcal{f}$ Med 1978; 296: 839-44.

10 Goldschlager N, Selzer A, Cohn K. Treadmill stress tests as indicators of presence and severity of coronary artery disease. Ann Intern Med 1976; 85: 277-86.

11 Bruce RA, Kusumi F, Hosmer D. Maximal oxygen intake and nomographic assessment of functional aerobic impairment in cardiovascular disease. Am Heart f 1973; 85: 546-62.

12 Théroux $P$, Waters DD, Halpen C, Debaisieux J-C, Mizgala HF. Prognostic value of exercise testing soon after myocardial infarction. $N$ Engl f Med 1979; 301: 341-5.

13 Paine TD, Dye LE, Roitman DI, et al. Relation of graded exercise test findings after myocardial infarction to extent of coronary artery disease and left ventricular dysfunction. Am $\mathcal{F}$ Cardiol 1978; 42: 716-23.

14 Castellanet MJ, Greenberg PS, Ellestad MH. Comparison of S-T segment changes on exercise testing with angiographic findings in patients with prior myocardial infarction. Am F Cardiol 1978; 42: 29-35.

15 Hellerstein HK, Prozan GB, Liebow IM, Doan AE, Henderson JA. Two step exercise test as a test of cardiac function in chronic rheumatic heart disease and in arteriosclerotic heart disease with old myocardial infarction. Am F Cardiol 1961; 7: 234-52.

16 Aronow WS, Harris CN. Treadmill exercise test in aortic stenosis and mitral stenosis. Chest 1975; 68: 507-9. 